\title{
COMMENTARY
}

\section{Should Business Training be a Required Element of Pharmacy Training?}

\author{
Michael J. Schuh, PharmD, MBA \\ Mayo Clinic Florida, Department of Pharmacy, Jacksonville, Florida
}

Corresponding Author: Michael J. Schuh, Mayo Clinic Florida, Department of Pharmacy, 4500 San Pablo Rd., Jacksonville, FL 32224. Tel: 904-953-2673. Email: Schuh.michael@mayo.edu

Submitted June 2, 2021; accepted August 25, 2021; ePublished September 2021

\begin{abstract}
Objective. Since pharmacists cannot be reimbursed for their clinical services as well as current providers listed under the Social Security Act, it is more difficult finding ways to financially support their services so these services may be more accessible to patients. Business training in pharmacy school may provide a foundation for pharmacists to create financially viable practice models and allow for better communication with administrative decision makers.

Discussion. Supporting pharmacist accessibility to deliver patient clinical services has been challenging because pharmacists are not listed as providers under Medicare via the Social Security Act. Because in many cases there is not sufficient financial support through reimbursement to cover pharmacist labor costs, pharmacists must show they save more in labor costs through cost-avoidance to be accessible to patients in a particular health care setting.

Conclusion. The provision of formal business training in pharmacy schools could more effectively assist graduate pharmacists in creating financially viable models of practice to increase pharmacist clinical service accessibility. Keywords: business training, pharmacy school, pharmacist services, reimbursement
\end{abstract}

\section{INTRODUCTION}

Pharmacists are not yet listed as medical providers under Medicare via the Social Security Act and therefore may not be able to bill Medicare and other government or commercial payers adequately for ambulatory clinical services rendered. ${ }^{1-2}$ The Senate and House of Representatives bills, S. 1362 and H.R. 1362 respectively called the Pharmacy and Medically Underserved Areas Enhancement Act (PMUEA), being reintroduced by the American Pharmacists Association (APhA) and the American Society of Health System Pharmacists (ASHP) is projected to remedy this issue in underserved areas of the United States. ${ }^{3}$ These bills endorse pharmacists billing and being reimbursed for pharmacist clinical services at the same rate as nurse practitioners and physician assistants. This rate is $85 \%$ the physician rate reimbursed by medicare. ${ }^{3}$ Even with passage of this legislation, business skills will be needed to assist in organizational acceptance and alignment with strategic objectives to implement such services efficiently with financial effectiveness to maximize return on investment (ROI).

Until legislation can be passed pharmacists often must justify their labor costs using cost avoidance rationale to provide ambulatory clinical services. ${ }^{4}$ Cost avoidance in this case is defined as costs not incurred due to better patient outcomes resulting in lower acute care health system utilization and lower subsequent costs to payers. To do this and explain the concept confidently and convincingly to administrative decision makers who would employ them or utilize their services requires basic business knowledge of labor costs balanced with the prospect of enough health care cost avoidance as a result of these pharmacist provided services to offset or more than offset the labor costs of employing pharmacists. Because this is a promise of ROI in the future for labor costs that must be paid in advance now, every pay period as wages until this savings are realized, it is a very tough sell to decision makers. In addition, the entity who would utilize and pay for these pharmacist provided services is not necessarily the beneficiary of the savings unless they are also the payer. ${ }^{5}$ Even worse, as the payer reaps the cost avoidance savings benefits from using these pharmacist clinical services, they may only share a small portion of these savings with the pharmacist service provider through rebates, lower payment penalties or other monetary rewards for the improved patient outcomes pharmacist services provide. Therefore, the labor costs of the pharmacist may still be a revenue negative proposition for the organization paying the pharmacist. The result is underutilization of pharmacist clinical skills, poorer patient outcomes and higher overall health care costs since ROI of pharmacist utilization in the ambulatory patient care setting may range from a respectable $29 \%$ to a whopping $1200 \% .^{6-7}$

\section{DISCUSSION}


What are the options to increase utilization of to use their clinical skills efficiently and effectively in an economic environment of oversupply, high need but lower demand than expected because of poor $3^{\text {rd }}$ party reimbursement? The options are dictated by the current system of reimbursement and costing. Pharmacists must make simple, clear financial arguments to senior administration decision makers about organizational costs avoided or must generate financially creative practice models of reimbursement for pharmacist clinical services. The best way to make these arguments is speaking the same financial language as administration decision makers, utilizing business training and terminology.

Health system pharmacist labor costs are already figured into diagnosis related group (DRG) payments to hospitals. Ambulatory clinical pharmacists cannot roll their labor costs into the sale of product as community pharmacists can. Because commercial payers many times follow Medicare's lead in paying for services, pharmacists cannot adequately bill third party payers either because of no or inadequate Medicare or commercial payment. Even with passage of PMUEA legislation, expansion may take many years before services are adequately paid for by 3rd party payers for the general population. This leaves one last viable practice model option that requires some amount of marketing and business acumen. Self-pay models of pharmacist clinical service provision.

Pharmacists and those who would hire them must convince the public through savvy marketing to self-pay for clinical services and through careful income and cost analysis, charge enough for those services to cover the cost of pharmacist labor and the overhead to provide services much as dentists, chiropractors and other health care professionals have in the past. Hence the need for increased business training in our pharmacy schools. ${ }^{8-13}$ Business training most applicable to pharmacists would be an overall introduction to business course with heavy emphasis on cost accounting and financial accounting concepts. Cost accounting covers the cost-avoidance argument for clinical services, financial accounting concepts would be useful with regard to the four primary financial statements would universally cover anything else. ${ }^{14-15}$ These courses could be structured as electives or longitudinal projects in the third or fourth year of training. One would not have to abbreviate clinical training or contract clinical rotations.

Without more business training to either explain financial benefit to implement the expansion of ambulatory clinical services or how to implement them financially and responsibly, pharmacists in the ever expanding ambulatory space must compete with other health care professions who can already bill adequately for services. ${ }^{12}$ This puts the profession at a dire disadvantage because midlevel providers such as physician assistants and advanced nurse practitioners may act as market substitutes for pharmacists, even though they have a lower level of pharmacology and therapeutic training. Without ability to bill for services effectively and adequately or enough understanding of business principles to effectively explain the cost avoidance benefit of pharmacist ambulatory services to decision makers, pharmacists will remain an expensive labor overhead cost that can only be afforded by some large, select health care employers. Worse, they will be forced to compete with others with less pharmacology and therapeutics training who can adequately bill for services for jobs in patient care. ${ }^{12}$

The logical answer in the short term is formal, pharmacy school business training. Formal training is multifold in benefit during a time of high demand or need when a valuable clinical resource is financially access restricted. It will teach marketing skills to sell pharmacist services economic benefit via cost avoidance to health systems. Collaborative models of practice would be better taught from a financial viewpoint on feasibility of pharmacists practicing collaboratively with provider offices to increase medical service delivery by sparing provider time for medication management. Business training could demonstrate how pharmacists may form independent practices, either solo or group, to provide services but bill institutions for the provision of clinical services without having to bill patients directly for pharmacist services that are not covered adequately by insurance or other third party payers. Training would assist in the ability of pharmacists to create self-pay or fee-for-service (FFS) practices where they may bill patients directly for clinical services. Business training would also enable pharmacists in the community environment better manage pharmacies in a competitive, low margin retail environment that may be mixed with some clinical activities such as immunizations, point of care testing, adherence services or other services a community pharmacy may offer. Chain store executives have mentioned that pharmacy school students do not have enough business training. ${ }^{16}$

As mentioned earlier, other professions have been at this payment crossroad in the past even though over time they have made progress with $3^{\text {rd }}$ party or insurance payment. Pharmacist ambulatory services are at this crossroad now. ${ }^{8-}$

${ }^{12}$ Some Medicare D and state platforms may pay for medication therapy management (MTM) but payment may not be enough to cover total labor and overhead costs of the minimum estimated $\$ 2.00$ to $\$ 3.00$ per minute needed. ${ }^{17-18}$

\section{CONCLUSION}

Some business training is already offered in pharmacy schools as Master's in Business Administration (MBA) training. ${ }^{16,19}$ However, graduates may not need or want the extra master's degree and business training may vary widely at non-MBA offering schools. An elective, one credit course, elective course series or clinical rotation offering as a solid foundation may be what is needed to help bridge these need-demand-supply service gaps between current state of 
underutilization and inadequate payment to the future state of routine adequate reimbursement and improved access to pharmacist clinical services for all patients.

\section{REFERENCES}

1. Social Security Act, Part E. Miscellaneous Provisions. Available at: https://www.ssa.gov/OP Home/ssact/title18/1861.htm. Accessed May 4, 2021.

2. ASHP FAQ: Pharmacist billing using "incident-to" rules non-facility (physician-based) ambulatory clinic. Date of Publication: March 2019. Available at: https://www.ashp.org/-/media/assets/pharmacy-practice/resourcecenters/ambulatory-care/incident-to-billing-2019.ashx. Accessed May 4, 2021.

3. Pharmacy and Medically Underserved Areas Enhancement Act. ASHP. Available at: https://www.ashp.org/Advocacy-and-Issues/Provider-Status/Pharmacy-and-Medically-Underserved-AreasEnhancement-Act?loginreturnUrl=SSOCheckOnly. Accessed July 22, 2021.

4. Pharmacy and Medically Underserved Areas Enhancement Act, H.R. 2759/S. 1362. Available at: https://pharmacist.com/Advocacy/Issues/Medicare-Provider-Status-Recognition. Accessed May 4, 2021.

5. Schuh MJ. An Analysis and Comparison of Medication Therapy Management Cost-Avoidance vs. Fee-forService Financial Models. Consult Pharm. 2015 May;30(5):291-7.

6. Ramalho de Oliveira D, Brummel AR, Miller DB. Medication therapy management: 10 years of experience in a large integrated health care system. J Manag Care Pharm. 2010 Apr;16(3):185-95.

7. Isetts BJ, Schondelmeyer SW, Artz MB, Lenarz LA, Heaton AH, Wadd WB, Brown LM, Cipolle RJ. Clinical and economic outcomes of medication therapy management services: the Minnesota experience. J Am Pharm Assoc (2003). 2008 Mar-Apr;48(2):203-214.

8. U.S. Department of Health and Human Services Oral Health Coordinating Committee. U.S. Department of Health and Human Services Oral Health Strategic Framework, 2014-2017. Public Health Rep. 2016;131(2):242-257.

9. Cooper RA, McKee HJ. Chiropractic in the United States: trends and issues. Milbank Q. 2003;81(1):107-138.

10. Committee on Accessible and Affordable Hearing Health Care for Adults; Board on Health Sciences Policy; Health and Medicine Division; National Academies of Sciences, Engineering, and Medicine; Blazer DG, Domnitz S, Liverman CT, editors. Hearing Health Care for Adults: Priorities for Improving Access and Affordability. Washington (DC): National Academies Press (US); 2016 Sep 6. 3, Hearing Health Care Services: Improving Access and Quality. Available at: https://www.ncbi.nlm.nih.gov/books/NBK385310/. Accessed 27 May 2021.

11. Coulam RF, Gaumer GL. Medicare's prospective payment system: A critical appraisal. Health Care Financ Rev. 1992;1991(Suppl):45-77.

12. Urick BY, Meggs EV. Towards a Greater Professional Standing: Evolution of Pharmacy Practice and Education, 1920-2020. Pharmacy (Basel). 2019;7(3):98. 2019 Jul 20.

13. CMS Advanced Practice Registered Nurses, Anesthesiologist Assistants, and Physician Assistants Medicare Learning Booklet. Available at: https://www.cms.gov/Outreach-and-Education/Medicare-Learning-NetworkMLN/MLNProducts/Downloads/Medicare-Information-for-APRNs-AAs-PAs-Booklet-ICN-901623.pdf. Apr 2020. Accessed 27 May 2021.

14. Accounting Tools. The Four Basic Financial Statements. 2021. Available at: https://www.accountingtools.com/articles/the-four-basic-financial-statements.html. Accessed July 22, 2021.

15. What is Cost Accounting? The Basics. Accounting Degree Review. Available at: https://www.accountingdegree.org/cost-accounting-concepts/. Accessed July 22, 2021.

16. Drug Store News. Joint PharmD/MBA programs offer students a differentiating factor. Available at: https://drugstorenews.com/pharmacy/joint-pharmd-mba-programs-offer-students-a-differentiating-factor. Dec 2018. Accessed 27 May 2021.

17. Medication Therapy Management Services: A Critical Review. The Lewin Group. 2005 May. Available at: https://pharmacistsprovidecare.com/sites/default/files/medication therapy management critical\%20review.pdf. Accessed Aug 13, 2021.

18. Nuffer W, Trujillo T, Griend JV. Estimated Potential Financial Impact of Pharmacist-Delivered Disease Management Services Across a Network of Pharmacies in Rural Colorado. J Manag Care Spec Pharm. 2019;25(9):984-988.

19. Affordable College Degrees. College Affordability Guide. Available at: https://www.collegeaffordabilityguide.org/subjects/pharmacy/. Accessed Aug 13, 2021. 